5) Aethyl-Phthalidin $=\mathrm{C}^{16} \mathrm{H}^{8}\left(\mathrm{C}^{4} \mathrm{H}^{5}\right) \mathrm{N}=\mathrm{C}^{20} \mathrm{H}^{13} \mathrm{~N}$. Ist bei gewöhnlicher Temperatur flüssig, riecht dem Phthalidin ähnlich, nur weniger durchdringend und destillirt beinahe unverändert über.

Salzsaures Aethyl-Phthalidin löst sich im Wasser und krystallisirt in silberglänzenden Schuppen.

Jodwasserstoffsaures Aethyl-Phthalidin ist dem salzsaurem Salze ähnlich. (Lucien Dusart; Ann. de chim. et de phys. 3. sér. Novbr. 1855. tom. XLV. pag. 332-339.)

Dr. H. Ludwig.

\title{
Stickstoffgehalt von Pflanzenaschen.
}

Beim Auflösen der Runkelrübenasche in Wasser und Kochen der Auflösung entweicht Ammoniak, herrührend von der Zersetzung einer nicht unbeträchtlichen Menge von cyansaurem $\mathrm{Kali}=\mathrm{KO}, \mathrm{C}^{2} \mathrm{NO}$, welches sich beim Glühen der stickstoffhaltigen Runkelrübenkohle mit dem kohlens. Kali der Asche gebildet hat. Aus cyansaurem Kali und Wasser entsteht beim Kochen mit alkalischem Wasser kohlensaures Kali und kohlensaures Ammoniak.

$\mathrm{KO}, \mathrm{C}^{2} \mathrm{NO}+4 \mathrm{HO}=\mathrm{KO}, \mathrm{CO}^{2}+\mathrm{H}^{4} \mathrm{NO}, \mathrm{CO}^{2}$.

Ausser dem cyansauren Kali findet sich auch eine deutlich nachweisbare Menge von Cyankalium = blausaurem Kali in der wässerigen Lösung der Runkelrübenasche; denn die Kohlensäure, welche beim Ansäuern der Aschenlösung mit Weinsäure entweicht, besitzt den charakteristischen Geruch der Blausäure, und eine Portion der Lösung mit Kalilauge und Eisenvitriol vermischt giebt nach einstündigem Stehen beim Ansäuern mit Salzsäure eine Abscheidung von Berlinerblau. (Dr. H. Ludwig, Grundzzige der analyt. Chem. unorg. Substanzen, Jena 1851. S. 449.)

Boussingault hat die Mengen des Stickstoffs in einigen Pflanzenaschen ermittelt. Er fand in der Asche von Lupinenund Bohnenpflanzen 0,01 Proc. Stickstoff; in der Heuasche 0,404 Proc., in der Asche von Weizengarben 0,577 Proc., in der Erbsenasche 0,312 Proc., in der Haferasche 0,75 Proc., in der Queckenwurzelasche 0,34 Proc., in der Sonnenblumenasche (Helianthus) 0,27 Proc. und in der Runkelblätterasche 0,89 Proc. Stickstoff $=4$ Proc. Cyankalium. (Boussingault, Recherches sur la végétation; Annal. 'de chim. et de phys. 3. sér. Fevr. 1855. pag. 149 -223.) Dr. H. Ludwig. 